\title{
International Infectious Disease Society for Obstetrics and Gynecology-USA
}

In the summer and fall of 1995, the International Infectious Disease Society for Obstetrics and Gynecology-USA was founded, with a commitment to the discipline of infectious disease and the health care of women worldwide. Scientists from other corners of the world have different clusters of diseases, different laboratory approaches, and new methods of problem solving that often shed light on unresolved questions regarding society. By establishing this organization, the founding members have succeeded in their goal to share knowledge through freer access to infectious disease specialists around the world.

Published in this issue are the abstracts of the first meeting of the International Infectious Disease Society for Obstetrics and Gynecology-USA held in Boulder, CO, on April 27-29, 1996. While the readers can judge for themselves the quality of the abstracts, what cannot be conveyed in writing are the zest of the discussions and the camaraderie of those attending the meeting. The American and international members as well as guests were enthusiastic about our new organization and plans for the next meeting in Nevada in the spring of 1997. We share their anticipation of an exciting and stimulating event.

William J. Ledger, President Mark G. Martens, 1996 Annual Meeting Program Chairman Department of Obstetrics and Gynecology New York Hospital/Cornell Medical Center New York, New York 


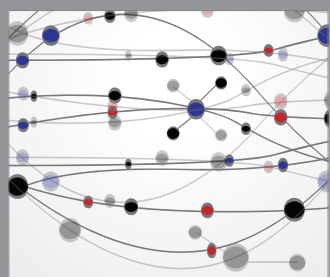

The Scientific World Journal
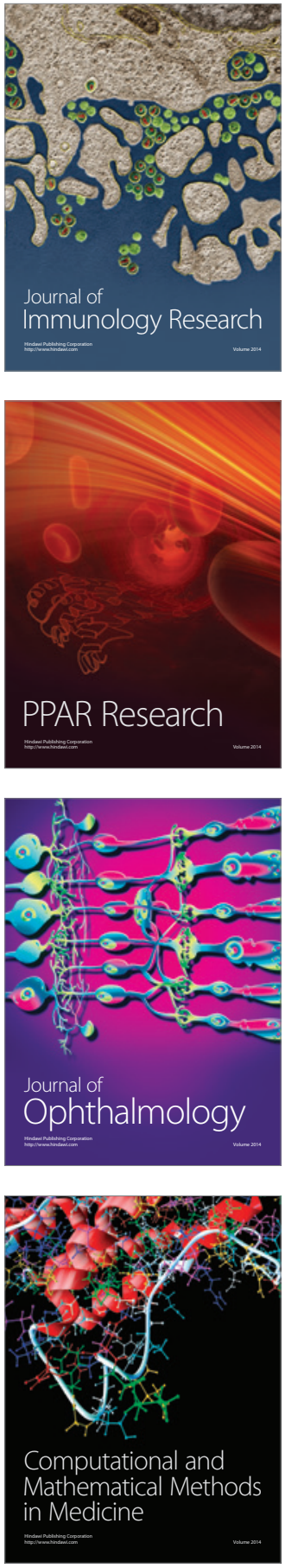

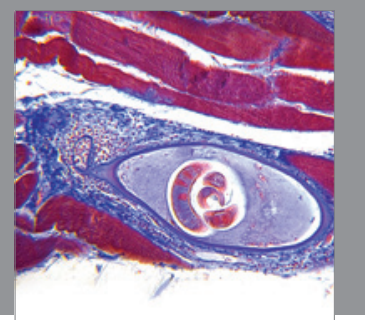

Gastroenterology

Research and Practice
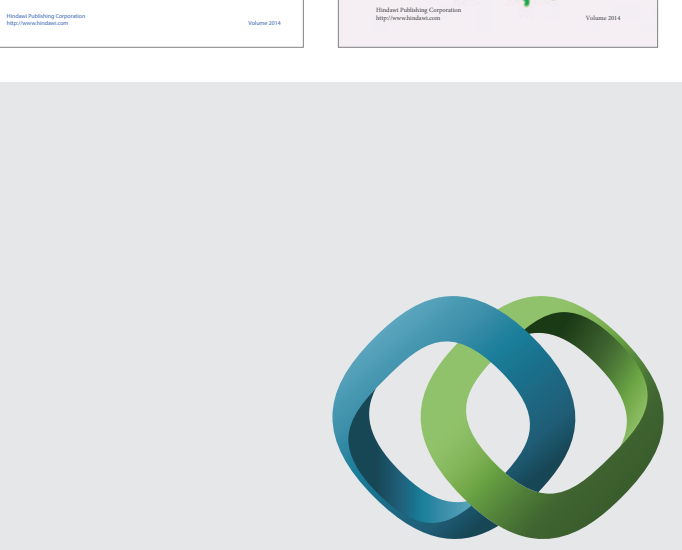

\section{Hindawi}

Submit your manuscripts at

http://www.hindawi.com
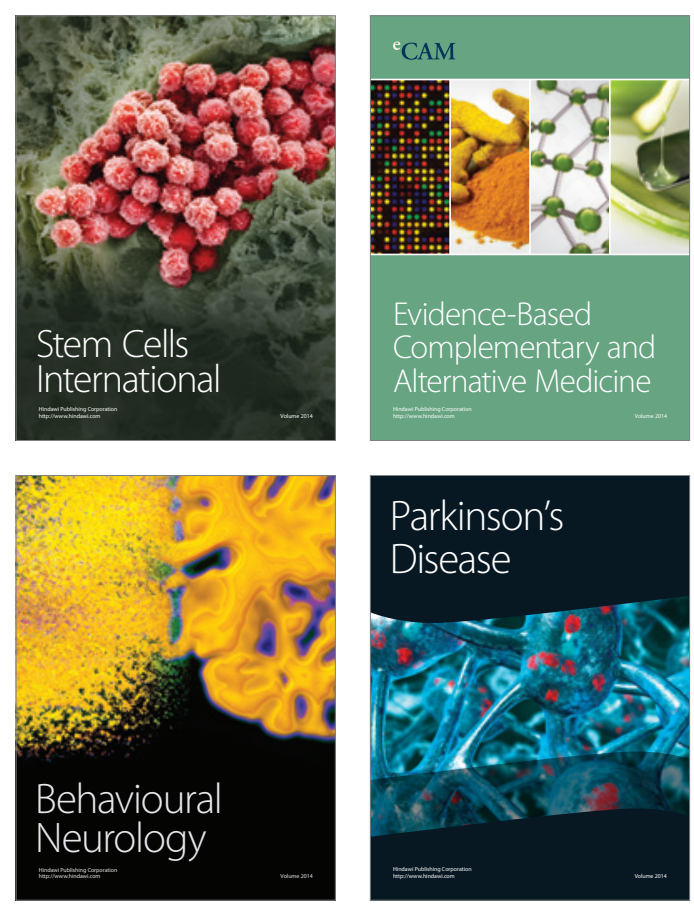

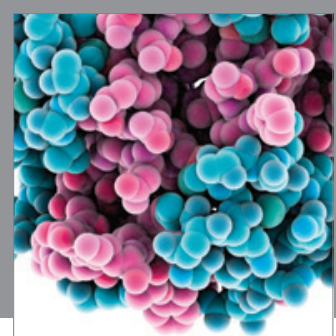

Journal of
Diabetes Research

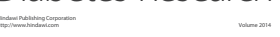

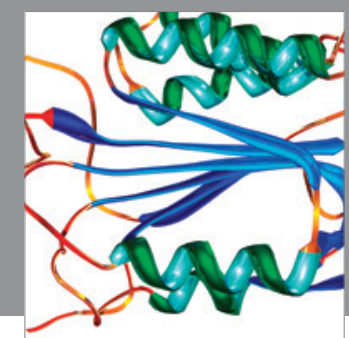

Disease Markers
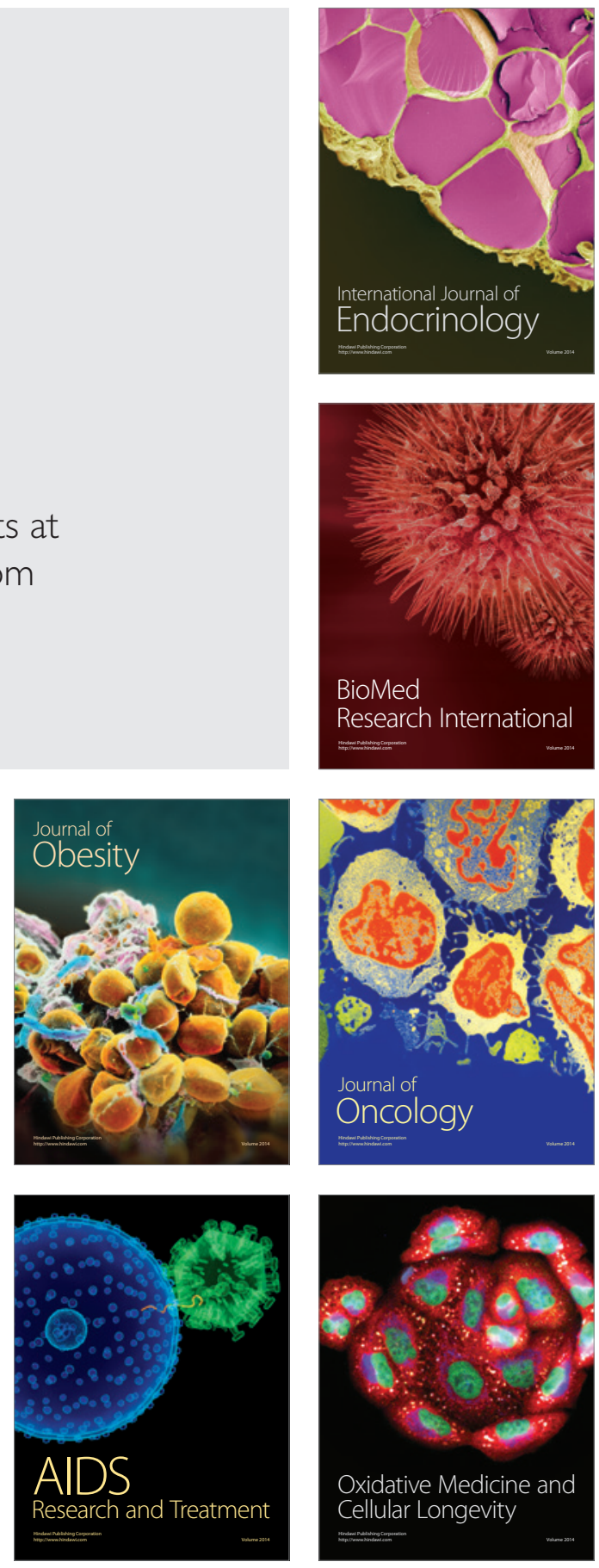